\title{
NEUVOSTOURHEILUN NOUSU JA TUHO
}

\author{
Hannu Itkonen \\ professori, Jyväskylän yliopisto
}

Venäjän keisarikunta sortui keväällä 1917 tapahtuneeseen porvarilliseen vallankumoukseen. Sitä seurasi saman vuoden syksyllä, lokakuussa paikallista kalenteria, bolsevikkien suorittama uusi vallankumous, jonka jälkeen maa ajautui veriseen ja laajoille alueille levittäytyneeseen sisällissotaan. Taistelujen, köyhyyden ja kurjuuden oloissa ihmisille ei tullut ensimmäisenä mieleen urheilun ja liikunnan harrastaminen. Vasta Neuvostoliitto-nimisen valtion tultua perustetuksi (1922) ryhdyttiin itäisessä naapurimaassamme pohtimaan myös urheilun ja laajemminkin ruumiillisuuden kysymyksiä.

Sisällissodan seurauksena maassa vallitsi pula miltei kaikesta. Ratkaisuksi nähtiin tarkasti kontrolloidun liittovaltion muodostaminen. Keskusjohtoiseen suunnitelmatalouteen tukeutuen tuotannolliset tavoitteet asetettiin viisivuotiskausille ja vuodeksi kerrallaan. Suunnitelmallisuus ulotettiin myös paikallistasolle, jolloin tarvittavien tuotteiden valmistaminen perustui alueelliseen työnjakoon. Päätavoitteiksi asetettiin maan sähköistäminen, raskaan teollisuuden rakentaminen ja maatalouden kollektivisointi. Myös väestön sivistystason kohottaminen nähtiin välttämättömäksi, sillä neuvostovallan alkuaikoina ainoastaan kolmannes väestöstä oli lukutaitoisia. Osana yhteiskunnan mittavista muutoksista olivat väestön pakkosiirrot ja vankityövoiman käyttö, joiden seurauksena kymmeniä tuhansia ihmisiä menehtyi kurjissa olosuhteissa. ${ }^{1}$

\section{Ruumiillisuuden valtiollistaminen}

Neuvostoliiton urheilun organisointi toteutui sangen omintakeisesti. Ensinnäkin, aikaisempien sukupolvien liikuntakulttuurista perinnettä ei voitu juurikaan hyödyntää. Vallankumouksen myötä tsaarinaikaiset liikunnan ja urheilun muodot eivät kelvanneet neuvostourheilun perustaksi. Vallankumousta edeltävä liikuntakulttuuri oli koostunut ylhäisöpiirien säätyläisliikunnasta ja sotilasurheilusta. Venäjän keisarillisen armeijan liikkumismuotoja olivat etenkin ratsastus, ammunta ja hiihto.

Venäjä oli hakeutunut jo 1890-luvulla mukaan kansainväliseen urheilutoimintaan. Maa oli perustamassa vuonna 1894 Kansainvälistä olympiakomiteaa ja osallistui vuonna 1908 Lontoon ja neljää vuotta myöhemmin Tukholman olympiakisoihin. Lisäksi se liittyi vuonna 1912 myös kansainväliseen jalkapalloorganisaatioon. ${ }^{2}$ Venäjä ei menestynyt ensimmäisissä olympiakisoissa kovin hyvin, mutta Lontoossa se saavutti kolme ja Tukholmassa viisi mitalia. Venäjän lipun alla urheilleet suomalaiset saalistivat Tukholman kisoista 26 mitalia. Maat kohtasivat Tukholman kisoissa kesäkuun 30. päivänä 1912 jalkapallo-

1 M. P. Kim et al., toim., Neuvostoliiton historia: Sosialismin aikakausi (Moskova: Kustannusliike Edistys, 1978), 229-243; Anne Applebaum, Gulag: A History of the Soviet Camps (London: Penguin Books, 2003), 73-85.

2 Barbara Keys, "Soviet Sport and Transnational Mass Culture in the 1930s," Journal of Contemporary History 38, no. 3 (2013): 416. 
ottelussa, jonka Suomi voitti selviten jatkopeleihin. $^{3}$

Toisekseen, urheilu liitettiin yhteiskuntaa valtiollistettaessa laajempaan ruumiillisuuden normittamiseen. Jo vuonna 1918 bolsevikit olivat säätäneet asetuksen sotataidon oppivelvollisuudesta. Vsevobuts-nimellä tunnetun sotilasurheiluasetuksen tavoitteena oli saattaa yleinen sotilasvalmennus osaksi sosialistisen yhteiskunnan rakennustyötä. ${ }^{4}$ 1920-luvulla ruumiinkasvatus keskittyi ennen kaikkea sotilaallisten valmiuksien ja työkuntoisuuden kehittämiseen, joita palvelemaan urheiluharrastukset asemoituivat sujuvasti. ${ }^{5}$ Kilpaurheilu ei ollutkaan neuvostovallan parina ensimmäisenä vuosikymmenenä keskeisessä asemassa yhteiskunnallisissa käytännöissä. ${ }^{6}$

Kolmas urheilun omintakeisuutta synnyttänyt tekijä oli vallankumouksen myötä käynnistynyt kulttuurin uudelleenorganisointi. Mitenkään mutkattomasti ei vallankumoukselliseen kulttuuriin päädytty; 1920-luvun kulttuurielämä oli täynnä mitä erilaisimpien näkemysten ja suuntausten vuorovaikutusta ja taistelua. Tavoitteena oli luoda vaihtoehto porvarilliseksi luokitellulle rappiokulttuurille. Uutta kumouksellista taidetta ryhtyi toteuttamaan useilla kulttuurin aloilla toiminut Proletkult-liike. Etenkin alkuvaiheissa oltiin valmiita tuhoamaan kaikki vanha ja tuottamaan uutta puhtaasti proletaarista taidetta. ${ }^{7}$ Liikkeen hen- gessä myös urheilua alettiin organisoida aivan uusista lähtökohdista. Vallankumouksellista fyysistä kulttuuria luotiin teatraalisissa suurten joukkojen ulkoilmaesityksissä. ${ }^{8}$ Moskovan Varpusvuorilla järjestettyjä joukkotilaisuuksia pidettiin vaihtoehtona porvarillisen individualistiselle kilpaurheilulle.

Muun kulttuurin tavoin myös ruumiinkulttuurin suunnasta käytiin 1920-luvulla ankaraa kamppailua. Osa kulttuuriväestä ja etenkin Proletkult-liike vastusti kilpaurheilua. Runoilija Vladimir Majakovski totesi, että "maailmassa ei ole parempia vaatteita kuin ruskeaksi paahtunut ja raikas iho". ' Keskusteluihin osallistuivat myös "hygienisteiksi" nimetyt, jotka koostuivat fysiologian, anatomian, hygienian ja terveydenhuollon ammattilaisista. Ymmärrettävästi "hygienistien" tavoitteena oli yleinen terveyden edistäminen, joten he vastustivat kilpaurheilua. Esimerkiksi painonnostoa, nyrkkeilyä ja voimistelua "hygienistit" pitivät irrationaalisina ja jopa terveydelle vaarallisina. ${ }^{10}$

Osa neuvostokansalaisista alkoi kuitenkin kiinnostua kilpaurheilusta. Vuonna 1921 Moskovassa perustettiin sinänsä vähämerkitykselliseksi koettu ja siksi pelkästään sotilasvalmennusjärjestelmän alaosastoksi nähty Punainen urheiluinternationaali (PUI). ${ }^{11}$ Sen viralliseksi nimeksi kirjattiin Kansainvälinen fyysisen kulttuurin työläisten ja talonpoikien liitto.

3 Kenth Sjöblom, "Autonominen olympiamaa," teoksessa Sadan vuoden olympiadi: Suomalaisen olympialiikkeen historia, toim. Vesa Tikander et al. (Porvoo: WSOY, 2007), 10-39.

4 James Riordan, Sport in Soviet Society (London: Cambridge, 1977), 68-70.

5 Hannu Itkonen, \& Pentti Stranius, Liikettä Venäjän Karjalassa: Tutkimus liikuntakulttuurin muutoksesta, Karjalan tutkimuslaitoksen julkaisuja 137 (Joensuu: Joensuun yliopisto, 2002), 25-35.

6 Timo Metsä-Tokila, "Tiellä olympialaisiin: Huipulle tähtäävän urheilun ja koulutuksen yhdistäminen Neuvostoliitossa ja Venäjällä," Idäntutkimus 7, no. 3-4 (2000): 71.

7 Pekka Pesonen, Venäjän kulttuurihistoria (Helsingin yliopiston Lahden tutkimus- ja koulutuskeskus, 1998), $170-171$.

8 Henning Eichberg, "Body Culture," teoksessa Routledge Companion to Sports History, toim. S. W Pope \& John Nauright (London: Routledge, 2010), 166.

9 Itkonen \& Stranius, Liikettä Venäjän, 23.

10 Riordan, Sport in Soviet, 95-96.

11 Helge Nygrén, Punainen olympia: TUL kansainvälisen työläisurheilun vaiheissa 1920-30-luvuilla (Helsinki: Tammi, 1968), 17. 
Keskeiseksi tavoitteeksi määritettiin työläisurheiluliikkeen johdattaminen proletariaatin vallankumouksen palvelukseen ja yhteistyön rakentaminen sosialidemokraattisten työläisurheilijoiden kanssa yhteisrintamataktiikan hengessä. ${ }^{12}$

Työväen Urheiluliiton historiankirjoittajan Seppo Hentilän mukaan PUI:n perustamiseen johti kolme tekijää. Ensinnäkin siihen vaikutti kansainvälinen urheilupolitiikka. Vuoden 1920 syyskuussa työläisurheilulle oli Luzernissa perustettu kattojärjestö (LUI). Kommunistit huolestuivat sen perustamisesta peläten järjestöstä muodostuvan johtava kansainvälinen työläisurheilujärjestö. PUI:n perustaminen johti osaltaan työläisurheilun jakautumiseen kahteen kilpailevaan leiriin. Toisekseen Neuvosto-Venäjän urheilu oli uudelleenorganisoinnin alaisena, joten PUI:Ile määrittyi uusia tehtäviä. Kolmas perustamiseen johtanut tekijä oli eräissä Keski-Euroopan maissa alkanut työväen urheiluliikkeen jakautuminen sosialidemokraattien ja kommunistien leireihin. ${ }^{13}$

Neuvostoliiton ruumiinkulttuurin tärkein osa oli 1920-luvulla Vsevobuts-järjestelmä, jonka toimintaa organisoi vuonna 1920 perustettu Korkein liikuntaneuvosto. Vsevobuts-järjestelmä koostui "vapaaehtoisesta" nuorisolle tarkoitetusta ruumiillisesta koulutusjaksosta. 600 tunnin valmennus sisälsi muun muassa marssiharjoituksia, sotilasharjoitteita, pelejä, voimistelua ja yleisurheilua. Vsevobutsin puitteissa liikunnallisia harjoituksia koordinoi Fyysisen kasvatuksen ja urheilun osasto, jonka toimet ulottuivat nopeasti tehtaisiin, kouluihin ja oppilaitoksiin. Kyseisiin organisaatioihin perustettiin sotilasurheilukerhoja, joiden toi- minta perustui 1920 -luvun vuosina ainakin osittain vapaaehtoisuuteen. ${ }^{14}$

Punainen urheiluinternationaali ei ollut pitkäikäinen organisaatio. Vuonna 1937 se lakkautettiin. Kommunistisen puolueen johdolla toimineen valtaorientoituneen järjestön toiminta kävi tarpeettomaksi. Sotilaskuntoisuuden ylläpitoon ei enää tarvittu PUI:n kaltaista organisaatiota. ${ }^{15}$ PUI kävi tarpeettomaksi myös sikäli, että kilpaurheilusta vastasivat sitä varten perustetut organisaatiot. Merkittävään asemaan olivat nousseet urheilun lajiorganisaatiot, jotka keskittyivät huolehtimaan oman lajinsa menestyksestä. Lisäksi muun muassa armeija, turvallisuuspalvelu, miliisi ja tuotantolaitokset olivat pystyttäneet omat urheiluorganisaationsa joukkueineen ja yksilöurheilijoineen.

Neuvostoliiton liikuntakulttuurin alkuaskeleet olivat tulevaisuuden suunnanetsintää sekä poikkeavien tulkintojen esittämistä. Merkittäviä suunnanmäärittäjiä olivat Proletkultryhmäläiset, "hygienistit" ja armeija sekä vähitellen myös kilpaurheilun nimiin vannoneet toimijat. Suunnanetsintää osoittaa, että 1920-luvulla urheilun mallia haettiin muun muassa partioliikkeestä, Sokol-voimistelusta ja juutalaisten Maccabee-organisaatiosta sekä joistakin porvarillisista urheiluorganisaatioista. Nuoren sosialistisen valtion säilyttämiseen tähtäävä sotilaskuntoisuuteen kasvattaminen johti urheilun militarisointiin. ${ }^{16}$

\section{Urheilun suosion kasvu}

Moskovassa järjestettiin PUI:n toimesta kesällä 1928 ensimmäiset spartakiadit. Neuvostoliitossa oli pantu merkille ns. porvarillisten

12 Seppo Hentilä, Suomen työläisurheilun historia, vol. 1, Työväen Urheiluliitto 1919-1944 (Hämeenlinna: Karisto, 1982), 141.

13 Hentilä, Suomen työläisurheilun, 142.

14 M. F. Buntsuk, Neuvostoliiton liikuntaorganisaatio, Liikuntatieteellisen Seuran julkaisu 71 (Helsinki: Liikuntatieteellinen Seura, 1979), 71, 12-13.

15 Joachim Raschke, "Zum Begriff der sozialen Bewegung?," teoksessa Neue Soziale Bewegungen in der Bundesrepublik Deutschland, toim. R. Roland \& D. Rucht (Frankfurt am Main: Campus Verlag, 1987), 19-29.

16 Riordan, Sport in Soviet, 68-69. 
olympiakisojen suosion kasvu. Spartakiadien järjestäminen ajoitettiinkin samaan vuoteen kuin Amsterdamissa pidetyt olympiakisat. Moskovan uudella Dynamo-stadionilla pidettyihin spartakiadeihin saapui osanottajiksi 650 työläisurheilijaa 19 maasta. Neuvostoliiton omassa joukkueessa esiintyi 4000 osanottajaa. Kisojen ideologisesta virityksestä viesti kisojen avajaisissa kajahtanut työn orjista ja sorron yöstä muistuttanut Kansainvälinen. Helge Nygrénin mukaan Moskovan spartakiadit olivat siihen mennessä järjestetyistä kansainvälisistä kilpailuista "ulkonaisesti todennäköisesti maailman mittavin urheilujuhla" ${ }^{17}$

Spartakiadeissa pääsivät esiintymään sekä joukkoliikunnan ja voimistelun nimiin vannovat Proletkult-linjan edustajat että urheilumenestystä tavoittelevat kilpaurheilijat ${ }^{18}$. Kansainvälisten vieraiden joukossa kilpaili myös suomalaisia, sillä mukana oli Työväen Urheiluliiton urheilijoita. TUL:n 80-henkinen joukkue menestyi kilpailuissa hyvin, sillä se saavutti kaikkiaan seitsemän voittoa, kahdeksan kakkossijaa ja monia muita kärkipään sijoituksia. Menestyneimpiä olivat yleisurheilijat Volmari Iso-Hollo, Hanna Kekäläinen ja Veikko Mutikainen, painija Kalle Ponsén, nyrkkeilijät Gunnar Bärlund ja Yrjö Paakki sekä uimari Irma Lumivuokko. TUL:n sosialidemokraattista johtoa kisamatka Neuvostoliittoon ei miellyttänyt, ja niinpä liittotoimikunta erotti syyskuun alussa kaikki spartakiadijoukkueeseen osallistuneet urheilijat. ${ }^{19}$

Vuoden 1928 lopulla Moskovassa järjestettiin talvilajien spartakiadit. Mittasuhteiltaan kisat olivat vaatimattomat verrattuna kesällä järjestettyihin spartakiadeihin. Kisoihin saapui 636 osanottajaa, jotka kilpailivat hiihdos- sa, pikaluistelussa ja ampumahiihdossa. Postin työntekijöille, palomiehille, rajavartijoille ja maanviljelijöille oli järjestetty omat kilpailunsa. ${ }^{20}$

Suomalaiset olivat merkittävästi mukana neuvostourheilun kansainvälisten suhteiden synnyttämisessä. Vuonna 1922 TUL teki yhteistyösopimuksen Neuvosto-Venäjän Fyysisen kasvatuksen korkeimman neuvoston kanssa kilpailusuhteiden järjestämisestä. Syyskuussa 1922 kilpailuyhteistyö käynnistyikin TUL:n jalkapallojoukkueen vieraillessa turnausmatkalla eri puolilla itäistä naapurimaata. Ottelut olivat Neuvostoliiton ensimmäinen virallinen kansainvälinen urheilukosketus. Urheiluinnostusta levittivät osaltaan myös sisällissodan seurauksena Neuvostoliittoon paenneet suomalaiset, jotka olivat jo kotimaassaan osallistuneet työläisurheilurientoihin. ${ }^{21}$

Vuoden 1928 spartakiadit lisäsivät urheilun kiinnostavuutta Neuvostoliitossa. Myös neuvostojohdon tekemä poliittinen linjaus siirtymisestä kansanrintamataktiikkaan vauhditti pyrkimyksiä kansainvälisten urheilusuhteiden lisäämiseen. Kansainväliset kilpailukosketukset johtivat myös vertailuasetelmiin. Neuvostojohdon olikin ryhdyttävä pohtimaan, miten urheilua tuli organisoida menestyksen saavuttamiseksi. Kysehän ei ollut pelkästään urheilukenttien vaan myös sosialismin ja kapitalismin välisestä mittelöstä. ${ }^{22}$

Spartakiadit lisäsivät urheilun kiinnostavuutta myös siten, että ne synnyttivät aivan uudenlaista neuvostojulkisuutta. Hyvissä ajoin ennen tapahtumaa ryhdyttiin julkaisemaan Spartakiada-lehteä, jossa opastettiin niin urheilijoita kuin urheiluyleisöäkin. Lehden kirjoituksissa korostettiin spartakiadien mer-

17 Nygrén, Punainen olympia 48-58.

18 Hannu Itkonen \& Kalervo Ilmanen, ”Neuvostourheilusta Venäjän sekajärjestelmään," Idäntutkimus 15, no. 4 (2008): 20-21.

19 Hentilä 1982, 215-220.

20 James Riordan, Sport, Politics and Communism (Manchester: Manchester University Press, 1991), 40.

21 Hentilä, Suomen työläisurheilun, 146-147.

22 Itkonen \& Ilmanen, ”Neuvostourheilusta Venäjän," 21. 
kitystä propagandan välineenä. Kisojen näyttävyyden suhteen haluttiin, että kilpailukatsomot olisivat täynnä yleisöä. Näin osoitettaisiin työläisurheilun joukkovoimaa. ${ }^{23}$

Neuvostoliitto ei osallistunut 1920-luvulla läntisten maiden urheilutoimintaan. Pyrkimyksenä oli kehittää omaa urheilukulttuuria kollektivismin hengessä vaihtoehtona kapitalistiselle kulutusorientoituneelle ja elitistiselle urheilulle. 1930-luvulla urheilusta muodostui massakulttuurin suosituin ilmiö. Tätä muutosta seurattiin myös Neuvostoliitossa. Vuonna 1934 urheilupolitiikkaa laajempi poliittinen linjaus kansanrintamapolitiikasta ja sen avulla fasismin vastustamisesta lisäsivät pyrkimyksiä solmia kansainvälisiä urheilusuhteita. Syntyneet kilpailukosketukset olivat omiaan modernisoimaan neuvostourheilua. Samalla jouduttiin pohtimaan myös sitä, millaisin menetelmin menestystä kyettäisiin saavuttamaan. $^{24}$

Yleisemmät 1930-luvulla toteutuneet muutokset vaikuttivat myös urheilun asemaan. Moshe Lewin on kuvannut muutosten mittavuutta seuraavasti:

Ajanjakson yleistä ilmapiiriä kuvastavat kaupungistuminen, teollistaminen, kollektivointi, puhdistukset ja näytösoikeudenkäynnit, koulutuksen yleistyminen, kulttuurin usein demagoginen väheksyntä, voimavarojen ja ihmisten mobilisointi, yhä tavallisimpien toimintojen julistaminen rikollisiksi, hallintorakenteiden kiihkeä luominen ja niin edelleen. Kaikki nämä ja monet muutkin kuuluvat kuohuvalle 1930-luvulle. Nämä huomattavat, miltei samanaikaisesti sattuneet tapahtumat ja prosessit niveltyivät keskenään, vaikuttivat toisiinsa ja synnyttivät historiallisia muutoksia tahtiin, johon on harvoin missään ylletty. Ja kaikki tapahtui suuren hämmennyksen, jopa kaaoksen ilmapiirissä.” ${ }^{25}$
Muutosten tuulet ulottuivat myös kulttuurielämään. Vallankumouksen jälkeen syntyneille kulttuurisuuntauksille laitettiin "suitset suuhun”. Kirjavat kulttuuriryhmittymät muutettiin puolue- ja valtiojohtoisiksi taiteilijaliitoiksi. Viralliseksi kulttuuri-ideologiaksi määriteltiin jo 1930-luvun alussa sosialistinen realismi, jonka noudattamista edellytettiin kaikilla taiteen aloilla. Sosialistisen realismin vaateiksi asetettiin puoluekantaisuus, kansanomaisuus ja tyypillisyys. Puoluekantaisuus merkitsi taiteen alistamista NKP:n poliittisiin linjauksiin. Kansanomaisuudella ymmärrettiin kansan elämän, olosuhteiden, tavoitteiden ja roolien oikeata kuvaamista. Tyypillisyyden kategorian mukaisesti taiteilijan tehtävänä oli luoda tyyppejä, joissa yhdessä roolihahmossa korostuu moninaisuus. Sosialistinen realismi edellytti tyyppien kuvastavan nimenomaisesti toimijoiden yhteiskunnallista taustaa ja luokkaluonnetta. ${ }^{26}$

Sosialistisen realismin mukaisesti varsinaiseksi tyyppien tyypiksi nähtiin positiivinen sankari, jonka tuli olla kaikin puolin esikuvallinen ja palvella työväenluokan etuja. Kirjallisuudessa tällaisiksi sankareiksi tulkittiin muun muassa Pavel Vlasovin hahmo Maksim Gorkin Äiti-romaanissa ja yhteisen edun nimissä uhrautuva Pavel Kortsagin Nikolai Ostrovskin teoksessa Kuinka teräs karastui. Kuvataiteessa sankarit olivat iloisia ja puhtoisia työläisiä niittämässä pellolla tai teknisen edistyksen symbolin, traktorin, selässä vilkuttavia ihmisiä. ${ }^{27}$

Tulkinta sosialistisen realismin sankarista vauhditti urheilijaesikuvien muodostumista. Urheilusankaruuden tuottaminen poikkesi taiteesta sikäli, että sankaruus lunastettiin menestymällä kilpakentillä. Myös edellä kuvatut yleisemmät yhteiskunnalliset muutokset

23 Mike O'Mahony, Sport in the USSR: Physical Culture-Visual Culture (London: Reaktion Books, 2006), 63-64.

24 Keys, "Soviet Sport," 414.

25 Moshe Lewin, Neuvostoliiton vuosisata (Helsinki: Like Kustannus, 2006), 96-97.

26 Pesonen, Venäjän kulttuurihistoria, 173-174.

27 Pesonen, Venäjän kulttuurihistoria, 174-175. 
loivat edellytyksiä urheilun suosion kasvulle. Urheilu nähtiin jopa vastavoimaksi kaupungistumisen myötä syntyneelle huliganismiksi nimetylle häiriökäyttäytymiselle. ${ }^{28}$

Vaikka kilpaurheilu kasvattikin suosiotaan neuvostoliittolaisessa urheilukulttuurissa, ei ideologisista tavoitteista kuitenkaan luovuttu. Vuonna 1933 neuvostolehdissä kehotettiin urheilijoita lyömään porvarilliset ennätykset. Lehdistö halusi Neuvostoliitosta maailman johtavan urheiluvaltion kaivaten voittoja, ennätyksiä ja menestystä. ${ }^{29}$ Myöskään joukkoliikuntaa ei unohdettu. Vuonna 1931 maassa otettiin käyttöön liikuntaohjelma, jonka tunnuksena oli "valmiina työhön ja maanpuolustukseen". Malli GTO-ohjelmana tunnetun fyysisen kasvatuksen organisointiin otettiin lordi Baden-Powellin partioliikkeen aktiviteeteista. ${ }^{30}$ GTO:sta muodostui Neuvostoliiton liikuntakasvatusjärjestelmän perusta testeineen ja suoritusmerkkeineen. Ohjelma sisälsi omat tavoitteensa eri ikäisille, ja sitä päivitettiin vuosikymmenten myötä. ${ }^{31}$ GTO on toiminnassa myös nyky-Venäjällä, jossa presidentti Vladimir Putin otti 2010-luvun puolivälissä 6-70-vuotiaille suunnatun ohjelman uudelleen käyttöön.

Neuvostourheilu kansainvälistyi 1930-luvun puolivälissä merkittävästi. Ensimmäisiä kilpailumatkoja tekivät nyrkkeilijät, juoksijat ja jalkapalloilijat. Vuonna 1934 Moskovan Spartakin pelaajat matkustivat ottelumatkalle Tšekkoslovakiaan, jossa kohtasivat Židenice Brnon ammattilaisjoukkueen. Vastustaja oli maailman huipulta, sillä tšekkien maajoukkue oli edellisenä vuonna voittanut maailmanmestaruuden lyötyään loppuottelussa Italian. ${ }^{32}$
Urheilijavaihtoa tehtiin muun muassa uinnissa, painissa, luistelussa, painonnostossa, pyöräilyssä, tenniksessä, miekkailussa, nyrkkeilyssä ja yleisurheilussa. Neuvostourheilijat vierailivat Skandinavian maissa, Turkissa, Ranskassa ja Belgiassa. Myös vastavierailuja tehtiin. Kilpailutapahtumat herättivät ylenpalttista kiinnostusta. Esimerkiksi vuoden 1936 tammikuussa, jolloin moskovalaisjoukkue voitti jalkapallo-ottelussa Pariisissa Ranskan mestarijoukkueen, oli Parc des Princes -stadionille saapunut 60000 katsojaa. $^{33}$

Urheilun kiinnostavuuden lisääntyessä ja harrastajamäärien kasvaessa piti myös neuvostomaan sisäistä kilpailutoimintaa ryhtyä organisoimaan. Kolmikymmenluvulla nousi jalkapalloilu suosituimmaksi urheilumuodoksi kaikkialla Neuvostoliitossa. Vuonna 1936 maassa perustettiin Moskovan Dynamon johdolla kansallinen liiga. Urheilun organisoimistapaa osoitti se, että keskenään kilpailevien joukkueiden taustavoimat löytyivät muun muassa salaisesta poliisista, sisäministeriöstä, armeijasta, rautateiltä ja tuotantolaitoksista. ${ }^{34}$

\section{Urheilun suurvallaksi}

Toisen maailmansodan jälkeisinä vuosina Neuvostoliiton oli arvioitava uudelleen suhteensa kansainväliseen urheilutoimintaan. Jo 1930-luvun kansainvälinen urheiluvaihto oli tuottanut ymmärrystä huippu-urheilun tasosta ja menestyksen edellyttämistä toimista. Ammattilaisurheilijoiden kohtaaminen esimerkiksi jalkapallossa vakuutti neuvostourheilun päättäjät ja valmentajat siitä, että urheilijoille oli luotava edellytykset täysipainoiseen harjoitteluun.

28 Lewin, Neuvostoliiton vuosisata, 99.

29 Barbara Keys, Globalizing Sport: National Rivalry and International Community in the 1930s (London: Harvard University Press, 2006), 164-165.

30 James Riordan, "The Unfinished Symphony Communism and Sport" (ISHPES Congress in Budapest, 1999).

31 Riordan, Sport in Soviet, 129-131.

32 Keys, Globalizing Sport, 166-168.

33 Keys, "Soviet Sport," 422.

34 Manfred Zeller, Sport and Society in the Soviet Union: The Politics of Football after Stalin (London: I.B. Tauris, 2018), 6. 
Neuvostourheilussa oli siirrytty ammattilaisuuteen osin jo ennen toisen maailmansodan vuosia. Moskovan Dynamo perustettiin kesäkuussa 1923 turvallisuuspäällikkö Feliks Dzerzinskin aloitteesta. Vielä tuolloin oli kyse ruumiillisuuden kolminaisuuden - työn, maanpuolustuksen ja urheilun - liitosta. 1930-luvun puolivälissä katseet suuntautuivat myös muihin mahdollisiin resurssitahoihin. Ammattiliittojen urheiluseuraksi perustettiin Spartak. Omat urheiluseuransa saivat myös rautatieläiset (Lokomotiv) ja armeija (TsSKA). ${ }^{35}$

Urheilun asemaa määritettiin myös lainsäädännöllä. Vuonna 1936 perustettiin valtiollisen liikuntaneuvoston tilalle Liikunta-ja urheilukomitea, mikä jo sinällään merkitsi urheilun merkityksen kasvua. Urheilijoiden yhteiskunnallista asemaa legitimoi vuonna 1939 säädetty asetus Urheilijan päivästä. Urheilusankarit nousivat kansakunnan merkkihenkilöiksi stahanovilaisten kaivosmiesten ja kommunististen iskurityöläisten rinnalle. ${ }^{36}$

Neuvostourheilun organisointiin 1930-luvulla toteutetut muutokset otettiin käyttöön heti toisen maailmansodan päätyttyä. Vuonna 1945 Neuvostoliitossa vieraili Suomen opetusministeriön delegaatio, jonka tavoitteena oli tutustua maan kulttuurielämään. Valtuuskuntaan kuulunutta entistä suojeluskuntamiestä mutta jatkosodan päätyttyä kommunistiksi kääntynyttä Klaus U. Suomelaa kiinnostivat etenkin urheiluasiat, joita hän käsittelikin vuosi vierailun jälkeen ilmestyneessä kirjassaan. Neuvostourheilun tarkastelussa Suomela hyödynsi käsiinsä saamaansa Izvestijan artikkelia, joka oli otsikoitu Edistämään urheilijain tuloksia. ${ }^{37}$

Tekstinsä alussa Suomela kehuu Neuvostoliiton urheilujärjestelmää, joka mahdollistaa urheilijoiden ennätystehtailun. Huomiota saa myös naisten aktiivinen osallistuminen urheiluelämään. Erityisesti Suomela nostaa esiin urheiluammattilaisuuden suhteen tehdyn täyskäännöksen sekä ennätysmiehille ja mestareille maksettavat mittavat rahapalkinnot. Esimerkiksi maailmanennätyksen saavuttaminen palkitaan rahallisella korvauksella, joka vastaa metallimiehen 7-8 kuukauden palkkaa. Suomelan arvion mukaan neuvostoammattilaisuus merkitsee uusien urheilijakykyjen esiinnousua kansainvälisissä kilpailuissa, jolloin myös muiden maiden on siirryttävä vastaavanlaiseen rahapalkintojen maksamiseen. ${ }^{38}$

Suomela teki urheilun ammattilaispohdinnoissaan samanlaisen suunnanmuutoksen kuin poliittisessa ajattelussaankin. Aiemmin amatörismin nimiin vannonut mies näki ammattilaisuuden sangen myönteiseksi ilmiöksi. Tekstissään Suomela nostaa esille myös suomalaisia ammattilaisurheilijoita, joiden suorituksia ei ole tarvinnut hävetä. Ammattiurheilijoiksi tulevat nimetyiksi "Hevonpäämme, Saarelamme, Tuomistomme, 'Gee Beemme' ja Kolehmaisen Viljamit”. Harjoitettua sala-ammattilaisuutta Suomela pitää urheilua demoralisoivana. Tieteessä, taiteessa ja talouselämässä noudatettu rahapalkkiokäytäntö tulisi ulottaa myös urheilun alueelle, jotta "sala-ammattilaisuuden piiloset" saataisiin loppumaan. Suomelalta lähtee viesti urheilujärjestöillekin. Elleivät neuvostourheilijat pääse "ammattilaisina kilpailuihin, niin heillä riittää kansainvälisyyttä omassa rannattomassa isänmaassaan”. ${ }^{39}$

Koska urheilu nähtiin Stalinin johdolla osaksi yhteiskuntajärjestelmien välistä kamppailua, kilpa-areenoille ei ollut syytä lähettää urheilijoita ilman menestysodotuksia. Niinpä Neuvostoliitosta matkasi Lontoon olympia-

35 Riordan, Sport in Soviet, 124-125; Riordan, Sport, Politics, 68-69.

36 Itkonen \& Stranius, Liikettä Venäjän, 25-26.

37 Klaus U. Suomela, Lensimme uuteen maailmaan: Nähtyä ja koettua Neuvostoliitosta (Lahti: Kansankirja, 1946), 188.

38 Suomela, Lensimme uuteen, 190-191.

39 Suomela, Lensimme unteen, 192. 


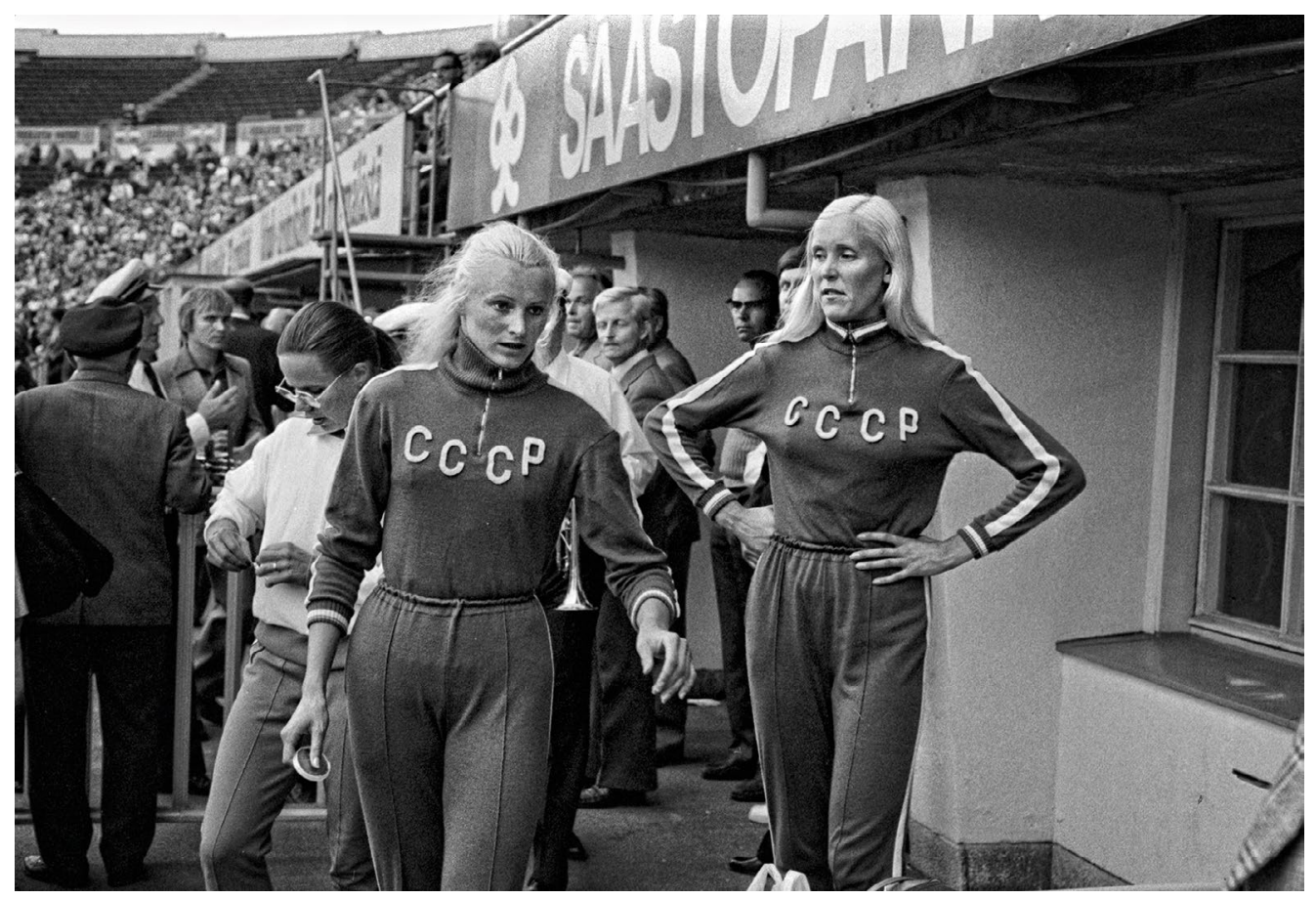

Neuvostoliitto kohtasi Suomen yleisurheilumaaottelussa vuonna 1974 Helsingissä. 400 metrin juoksun neuvostojuoksijattaret (vas.) Nadežda Kolesnikova (1949-2013) ja kansallisuudeltaan latvialainen Ingrida Barkane (s. 1948) Olympiastadionilla odottelemassa kilpailusuorituksensa alkua. Kuva: Alvar Kolanen.

kisoihin vuonna 1948 delegaatio, jonka tuli selvittää, miten neuvostourheilijat olisivat pärjänneet kisoissa. Laaditun raportin mukaan maan urheilijat olisivat menestyneet koitoksissa toiseksi parhaiten. Edelle olisi yltänyt ainoastaan Yhdysvaltain joukkue. Menestysmahdollisuuksia neuvostoliittolaiset näkivät etenkin jalkapallossa ja painonnostossa sekä yleisurheilussa, koripallossa, painissa, uinnissa, lentopallossa, luistelussa, hiihdossa, nyrkkeilyssä ja voimistelussa. ${ }^{40}$

Neuvostourheilijat astelivat olympiakentille Helsingin vuoden 1952 kisoihin. Neuvostoliiton ja muiden sosialististen maiden urheilijoille rakennettiin oma olympiakylä
Otaniemeen.$^{41}$ Ilman menestystä neuvostourheilijat eivät jääneet, sillä he kahmivat kisoista 71 mitalia, joista kultaisia oli 22, hopeisia 30 ja pronssisia 19. Mitalitaulukossa korkeammalle sijoittui ainoastaan Yhdysvallat 76 mitalillaan. ${ }^{42}$

Helsingin kisojen menestys ja poliittisen ilmapiirin muutos Stalinin vuonna 1953 tapahtuneen kuoleman jälkeen lisäsivät edelleen urheilun suosiota. NKP:n vuonna 1956 pidetyn XX edustajakokouksen päätökset ja suojasään nimellä tunnetun neuvostoyhteiskunnan poliittisen vaiheen on jopa katsottu luoneen edellytyksiä kansainväliselle urheilumenestykselle. ${ }^{43}$ Irina Makoveevan mukaan

40 Keys, "Soviet Sport," 431-432.

41 Jouko Kokkonen, "Oikeiden olympiakisojen maa," teoksessa Sadan vuoden olympiadi: Suomalaisen olympialiikkeen historia, toim. Vesa Tikander et al. (Porvoo: WSOY, 2007), 158-159.

42 "Olympic Games," luettu 6.9.2021, www.olympics.com/en/olympic-games.

43 Orlando Figes, Vallankumouksen Venäjä 1891-1991 (Helsinki: Siltala, 2021), 304. 
suojasään mahdollistamat toimet näkyivät Melbournen olympiakisojen menestyksessä loppuvuodesta $1956 .{ }^{44}$ Mitaleita neuvostourheilijat rohmusivat 98 kappaletta. Kultaisia he saavuttivat 37, hopeisia 29 ja pronssisia 32. Talviolympiakisoihin Neuvostoliitto osallistui ensimmäisen kerran samaisena vuonna 1956 Cortina d'Ampezzossa Italiassa. Ilman menestystä se ei jäänyt tuolloinkaan. Kultamitaleita tuli seitsemän, hopeaa kolme ja pronssia kuusi eli yhteensä 16 mitalia. ${ }^{45}$

Neuvostoliiton olympiamenestys jatkui aina maan romahtamiseen saakka. Viimeiset talviolympiakisat, joihin urheilijat osallistuivat Neuvostoliiton lipun alla, pidettiin Kanadan Calgaryssä vuonna 1988. Samana vuonna neuvostourheilijat kisasivat myös Soulin kesäkisoissa Koreassa. Oheinen taulukko 1. havainnollistaa Neuvostoliiton urheilijoiden saavuttamia mitaleita kesäolympiakisoissa. Niiden yhteismäärä on huikea 1010 . Menestystä tuli myös olympialaisissa talvikisoissa. Yhdeksiin kisoihin osallistuneet neuvostourheilijat ylsivät niissä kaikkiaan 194 mitaliin. Taulukko 2. havainnollistaa talvikisojen mitalimääriä.

Taulukko 1. Neuvostoliiton mitalit kesäolympiakisoissa 1952-1988.

\begin{tabular}{|l|c|c|c|c|}
\hline & kulta & hopea & pronssi & yhteensä \\
\hline Helsinki 1952 & 22 & 30 & 19 & 71 \\
\hline Melbourne 1956 & 37 & 29 & 32 & 98 \\
\hline Rooma 1960 & 43 & 29 & 31 & 103 \\
\hline Tokio 1964 & 30 & 31 & 35 & 96 \\
\hline Mexico 1968 & 29 & 32 & 30 & 91 \\
\hline München 1972 & 50 & 27 & 22 & 99 \\
\hline Montreal 1976 & 49 & 41 & 36 & 125 \\
\hline Moskova 1980 & 80 & 69 & 46 & 195 \\
\hline Soul 1988 & 55 & 31 & 46 & 132 \\
\hline
\end{tabular}

Taulukko 2. Neuvostoliiton mitalit talviolympiakisoissa 1956-1988.

\begin{tabular}{|l|c|c|c|c|}
\hline & kulta & hopea & pronssi & yhteensä \\
\hline Cortina 1956 & 7 & 3 & 6 & 16 \\
\hline Squaw Valley 1960 & 7 & 5 & 9 & 21 \\
\hline Innsbruck 1964 & 11 & 8 & 6 & 25 \\
\hline Grenoble 1968 & 5 & 5 & 3 & 13 \\
\hline Sapporo 1972 & 8 & 5 & 3 & 16 \\
\hline Innsbruck 1976 & 13 & 6 & 8 & 27 \\
\hline Lake Placid 1980 & 10 & 6 & 6 & 22 \\
\hline Sarajevo 1984 & 6 & 10 & 9 & 25 \\
\hline Calgary 1988 & 11 & 9 & 9 & 29 \\
\hline
\end{tabular}

44 Irina Makoveeva, "Soviet Sport as Cultural Phenomenon: Body and/or Intellect?," Studies in Slavic Cultures, no. 3 (2002): 9-32.

45 “Olympic Games," luettu 6.9.2021, www.olympics.com/en/olympic-games. 


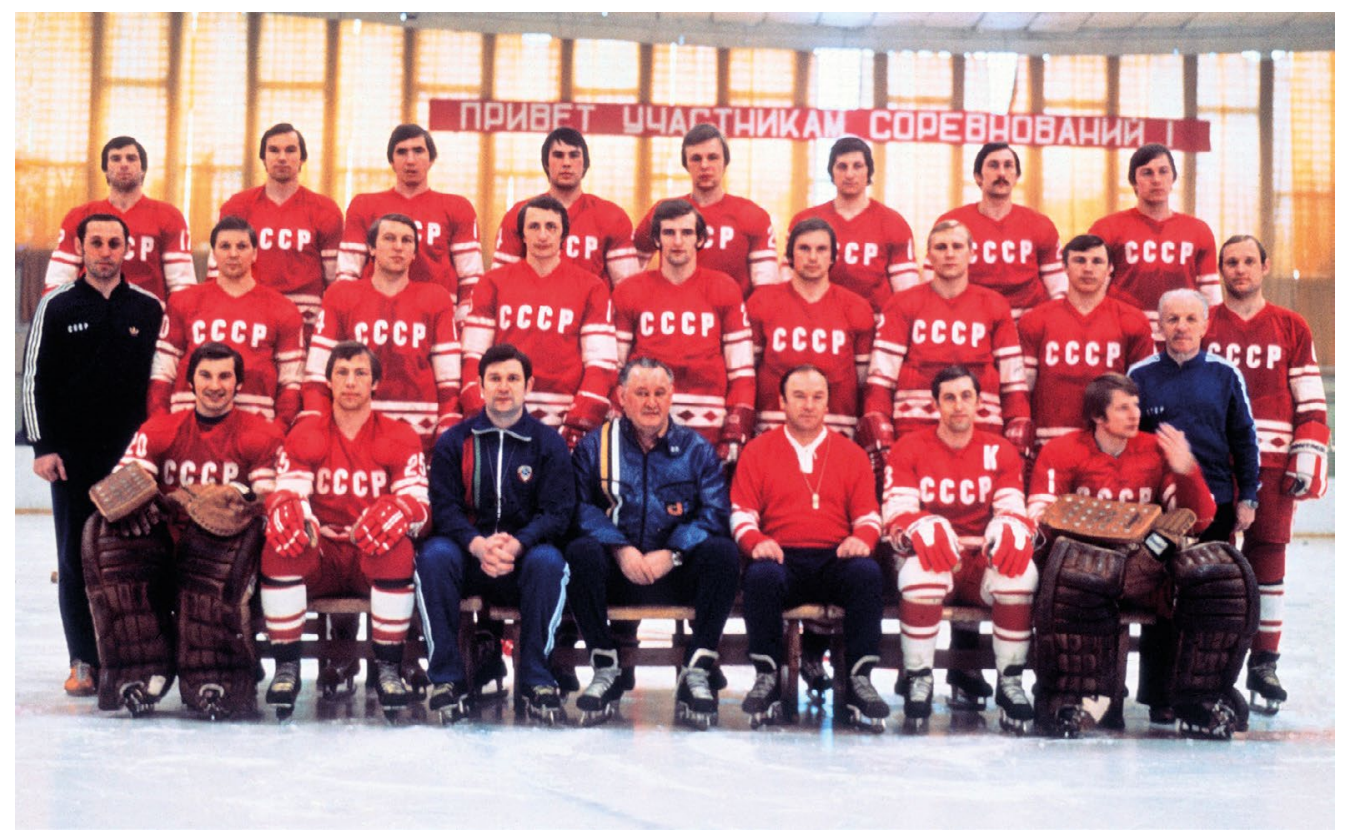

Neuvostoliiton legendaarinen jääkiekkomaajoukkue, Punakone, lähdössä menestyksekkääseen maailmanmestaruusjahtiin kevään 1975 kokoonpanossaan. Kuvassa vasemmalta oikealle eturivissä Vladislav Tretjak, Valeri Vasiljev, Vladimir Jursinov (valmentaja), Boris Kulagin (valmentaja), Konstantin Loktev (valmentaja), Boris Mihailov (joukkueen kapteeni) ja Aleksander Sidelnikov, keskirivissä Juri Detkin (hieroja), Aleksander Maltsev, Vladimir Šadrin, Aleksander Jakušev, Viktor Zluktov, Vladimir Lutšenko, Aleksander Gusev, Gennadi Tsigankov, Oleg Belakovski (lääkäri) ja Vladimir Petrov sekä takarivissä Valeri Harlamov, Viktor Šalimov, Aleksander Golikov, Sergei Babinov, Vjatšeslav Fetisov, Sergei Kapustin, Helmut Balderis ja Vasili Pervuhin. Kuva: LEHTIKUVA / Photo TASS / Vyacheslav Un Da-sin.

Kaikkiaan neuvostourheilijat saivat kesä- ja talviolympiakisoissa yhteensä 1204 mitalia. Vuoden 1984 Los Angelesin kisoissa mitalisaalis ei karttunut, sillä Neuvostoliitto boikotoi kisoja vastavetona Yhdysvaltain edellisten, Moskovassa järjestettyjen kisojen boikotille. Useiden länsimaiden jäätyä pois Moskovan kisoista niistä muodostui järjestäjämaan ja DDR:n mitalijuhla. Moskovan olympiakisat olivat joka tapauksessa neuvostourheilulle ja laajemminkin maan poliittiselle johdolle näytön paikka. Kisojen ajaksi kaupunki oli ehostettu näytöskuntoon, ja kaikki, jotka eivät olleet jollakin tavalla tekemisissä olympiakisojen kanssa, oli lähetetty maaseudulle pioneerileireille, datšoille tai valtion lomakeskuksiin. ${ }^{46}$
Neuvostoliitto-nimisen maan katoaminen kartalta pakotti pohdintoihin myös olympialiikkeessä. Vuoden 1992 Barcelonan kesäkisoihin ja Albertvillen talvikisoihin kehiteltiin omintakeinen ratkaisu. Venäläiset ja joidenkin entisten neuvostotasavaltojen urheilijat kilpailivat Itsenäisten valtioiden yhteisön (IVY / Unified Team) nimissä ja olympialipun alla. IVYä edustavan urheilijan voittaessa olympiakultaa tankoon vedettiin olympialippu ja soitettiin olympiahymni. Barcelonassa näin tehtiin 45 ja Albertvillessä yhdeksän kertaa.

\section{Menestystä laajalla rintamalla}

Neuvostourheilun tuotantokoneisto jauhoi tehokkaasti. Lukuisissa eri urheilumuodoissa 


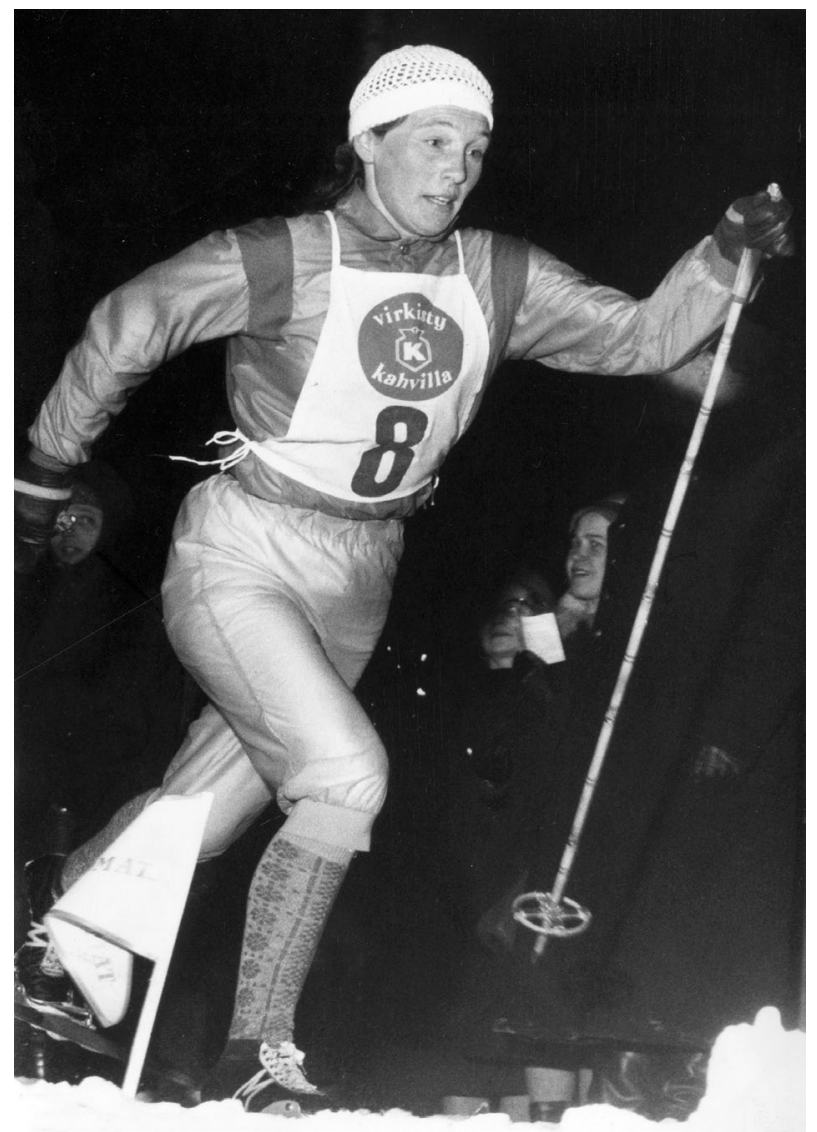

Alevtina Koltšina (s. 1930) oli moninkertainen maastohiihdon maailmanmestari ja olympiamitalisti 1950-luvun puolivälistä 1960-luvun lopulle ja yksi Neuvostoliiton naishiihdon suurista nimistä yhdessä Galina Kulakovan kanssa. Kuvassa Koltšina kilpailemassa Suomessa 1950-luvun lopulla. Hiihtouransa jälkeen hän muutti miehensä Pavel Koltšinin (1930-2010) - hänkin aiemmin kansainvälisesti menestynyt huippuhiihtäjä - kanssa Viroon, jossa asuu edelleen. Vuonna 1996 Koltšinit saivat Viron kansalaisuuden. Kuva: Urheilumuseo. saavutettiin menestystä, jonka perusteellinen tarkastelu tässä yhteydessä on mahdotonta. Huomio kiinnitettiin ennen kaikkea olympialajeihin, joissa kilpailu etenkin Yhdysvaltain kanssa muodostui muun politiikan ohessa urheilun kylmäksi sodaksi. Neuvostourheilun menestystekijöitä olivat valtioammattilaisuus, lääketieteen hyödyntäminen valmennuksessa farmakologisine ohjelmineen sekä tehokas urheilijoiden ja valmentajien rekrytointijärjestelmä. Erityisen tärkeäksi rekrytointi- ja valmennusjärjestelmäksi muotoutuivat urheilukoulut, joissa ammattivalmentajat ryhtyivät kasvattamaan lapsista ja nuorista tulevia huippu-urheilijoita.

Jalkapallo oli noussut Neuvostoliiton suosituimmaksi urheilumuodoksi jo 1930-luvulla.
Kansallisen sarjajärjestelmän perustamisen myötä pelin taso nousi Venäjän lisäksi myös muissa neuvostotasavalloissa. Muiden alueiden seurat haastoivat vähitellen moskovalaisseurojen Dynamon ja Spartakin valta-aseman. Ensimmäinen vakavasti otettava haastaja oli Kiovan Dynamo. Neuvostojalkapalloa tutkineen Manfred Zellerin mukaan pelin leviäminen synnytti myös alueellisia kannattaja- ja fanikulttuureita, jotka vaikuttivat koko neuvostoyhteiskunnan koheesioon ja tasavaltojen välisiin suhteisiin. ${ }^{47}$

Moskovan Dynamo teki pelimatkan Britanniaan jo vuonna 1945. Kokoonpanoa oli täydennetty muiden joukkueiden pelaajilla, joten kyseessä oli lähes maajoukkue. Urheilullisesti matka osoittautui menestyksekkääksi. Esimer- 
kiksi pääottelussa kaatui Arsenal maalein 4-3. Dynamon vierailu sai suurta huomiota sekä neuvostolehdissä että Britannian vasemmistolaisessa Daily Workerissa. Neuvostoliitossa vierailusta tehtiin musiikkikomedia, jonka nimi 19-9 symboloi tehtyjä maaleja. ${ }^{48}$ Jalkapallossa neuvostourheilu saavutti kansainvälistä menestystä myös maajoukkuetasolla. Neuvostoliitto voitti Melbournen olympiakisoissa kultamitalin vuonna 1956. Euroopan-mestaruuskilpailuissa maa voitti kultaa vuonna 1960 ja hopeaa vuosina 1964, 1972 ja 1988. Maailmanmestaruudesta kamppailtaessa parhaaksi saavutukseksi jäi Lontoon kisojen neljäs sija vuonna 1966.49

Urheilun kylmää sotaa käytiin olympiaareenoilla, joilla voitiin mitata saavutettujen mitalien määriä. Varsinaiseksi kylmän sodan lajiksi nousi jääkiekkoilu. Näin tapahtui siitäkin huolimatta, että NHL:n parhaimmat yhdysvaltalais- ja kanadalaisammattilaiset eivät MM-kilpailuihin osallistuneetkaan. Punakoneeksi kutsutun jääkiekkojoukkueen menestys hakee vertaistaan. Olympiakisoissa joukkue saavutti seitsemän kultaa, hopean ja pronssin. MM-kisoissa mestaruutta juhlittiin 22 kertaa. Hopeaa tuli seitsemän ja pronssia viisi kertaa.

Neuvostoliiton joukkuepelien maajoukkueet ovat voittaneet arvokilpailujen kirkkaimman mitalin sekä lukemattomia muita mitaleita myös koripallossa, lentopallossa, käsipallossa, vesipallossa ja jääpallossa. Yksilölajeissa menestystä on tullut lukuisissa urheilumuodoissa. Neuvostoliiton urheilutähdet ovat tulleet tunnetuiksi muun muassa yleisurheilussa, hiihdossa, ampumahiihdossa, taitoluistelussa, pikaluistelussa, painissa, painonnostossa, nyrkkeilyssä, ammunnassa, uinnissa, soudussa ja shakissa. Eniten olympiamitaleja on tullut yleisurheilussa (195), voimistelussa (184), painissa (116) ja painonnostossa (62). Talvilajeista parhaiten on menestytty hiihdossa (68), pikaluistelussa (60) ja taitoluistelussa $(24) .^{50}$

Merkille pantavaa on, että huomattavan osan Neuvostoliiton urheilumenestyksestä ovat saavuttaneet naiset. Voimistelussa ovat Neuvostoliiton väreissä kilpailleista naisista menestyneimpiä olleet ukrainalaiset Larisa Latinina saavutuksenaan 18 olympiamitalia ja Polina Astahova 10 mitalillaan. Valkovenäläinen Olga Korbut saavutti kilpaurallaan 6 olympiamitalia. Hiihdossa ovat puolestaan olleet menestyneimpiä naisia viidesti maailmanmestaruuden voittanut Galina Kulakova, joka lisäksi saavutti urallaan kahdeksan olympiamitalia, ja seitsenkertainen maailmanmestari Alevtina Koltšina viidellä olympiamitalillaan. Miesten puolella ovat menestyneimpiä olympiaurheilijoita olleet voimistelijat Nikolai Andrianov 15 mitalillaan ja Boris Sahlin saavutuksenaan 13 mitalisijaa. ${ }^{51}$

\section{Urheilun suurvalta ja perintö}

Neuvostoliittoa voidaan pitää kiistatta urheilun suurvaltana. Tultuaan kansainväliseen kilpailutoimintaan maa oli sekä olympiakisoissa että muissa arvokilpailuissa varsinainen mitalirohmu. Menestystä tuli sekä kesä- että talvilajeissa. Vaikka maa keskittyi etenkin olympialajeihin, niin ennätyksiin ja saavutuksiin se ylsi muissakin urheilumuodoissa laajalla rintamalla.

Neuvostoliiton menestymistä urheilussa edesauttoi se, että eri tasavaltojen kiinnostus lajeja kohtaan oli poikkeavaa. Pohjoisilla kylmemmillä alueilla oli luonnollista keskittyä hiihdon, luistelun, jääkiekon ja jääpallon kal-

48 Vesa Vares, Pallon herruus: Kuningaslajin valta ja lumo (Helsinki: Otava, 2018), 205-209.

49 "Olympic Football Tournament Melbourne 1956," luettu 6.9.2021, https://www.fifa.com/tournaments/ mens/mensolympic/melbourne1956; Stuart Mesham, toim., EURO 2020: Suuri jalkapallokirja (Helsinki: Readme.fi, 2021).

50 Itkonen \& Ilmanen, "Neuvostourheilusta Venäjän," 25.

51 "Olympic Games," luettu 6.9.2021, www.olympics.com/en/olympic-games. 
taisiin urheilumuotoihin. Etenkin ennen useiden talvilajien siirtymistä halleihin urheiltiin lumen ja pakkasen mahdollistamissa olosuhteissa. Joissakin tasavalloissa urheiluperinteet kantoivat aiempaa lajiharrastusta vielä neuvostoaikoinakin. Esimerkiksi Liettuan koripalloilun suosiota selittävät maan aiemmat yhteydet läntiseen suuntaan. Karjalan tasavallassa puolestaan keskityttiin hiihtoon, mäkihyppyyn, yhdistettyyn ja luisteluun, joista sillä olikin useita olympiaedustajia.

Neuvostoliiton valtiollisesti johdetussa urheiluorganisaatiossa valmennusprosessit oli tehty mahdollisimman kokonaisvaltaisiksi. Valmentajilla ja urheilijoilla oli käytössään lääketieteen uusimmat saavutukset. Farmakologisiin ohjelmiin eli dopingin käyttäjiksi valikoitiin kaikkein lahjakkaimmat urheilijat, joiden lääkeaineiden käyttöä valvottiin perusteellisesti. Neuvostoliiton urheiluorganisaatioissa tunnettiin hyvin, millaisin keinoin huippu-urheilussa toimittiin muissakin maissa. Neuvostourheilun menestyksen takasivat osaksi myös urheilijoiden harjoitusleirit ja kova treenikuri. ${ }^{52}$

Monissa lajeissa oli suoranaista tungosta olympiaedustajiksi. Esimerkiksi voimailulajeissa Neuvostoliiton sisäiset karsinnat olivat armottoman tiukkoja vääntöjä. Muiden tasavaltojen edustajat kritisoivatkin jatkuvasti, että venäläisurheilijoita suosittiin arvokisavalinnoissa. Neuvostoliitossa urheilumenestys tuotti paljon muutakin hyvää kuin mitaleita ja ennätyksiä. Urheilijoita hyödynnettiin sekä urheilun että järjestelmän esikuvina. Yksilöiden ja joukkueiden voitot nähtiin osoitukseksi sosialistisen yhteiskunnan paremmuudesta suhteessa kapitalistisiin valtioihin. Tällainen vertailu oli omiaan synnyttämään ”kylmää sotaa" myös urheiluareenoilla. Menestyneiden urheilijoiden elämisen olosuhteista huolehdit- tiin hyvin jo uran aikana. Urheilu-uran päätyttyä urheilutähdet palkittiin hyvillä työtehtävillä. Usein leipäpuu löytyi urheiluorganisaation erilaisista rooleista.

Millaisen perinnön neuvostourheilu jätti jälkeensä? Ensinnäkin urheilun asema on säilynyt edelleen vahvana paitsi Venäjällä myös monissa muissa entisissä neuvostotasavalloissa. Vuoden 1992 Barcelonan kesä- ja Albertvillen talviolympiakisoista IVY-maiden urheilijat saalistivat 135 mitalia. Tämän jälkeen venäläiset urheilijat ovat saavuttaneet kuusista kesäolympiakisoista (1996-2016) 425 mitalia ja seitsemistä talvikisoista (1994-2018) 137 mitalia. Hyvin on menestynyt myös Ukraina, jonka saalis on ollut kyseisen ajan kesäkisoista 121 ja talvikisoista seitsemän mitalia.

Leimallista neuvostoajan jälkeiselle urheilun organisoinnille on ollut valtiojohtoisuus. Näin on jouduttu menettelemään, koska Venäjän urheilussa ei ole olemassa Suomen kaltaista vahvaa kansalaisyhteiskuntaa. Urheilun organisointia Venäjän Karjalassa johtanut Jevgeni Shorohov kuvasi neuvostokauden jälkeistä aikaa seuraavasti:

Venäjällä olivat tyypillisiä 1990-luvulla hyvin monimutkaiset yhteiskuntapoliittiset prosessit. Neuvostoliiton hajotessa vuosikymmenen alussa markkinauudistukset johtivat pitkäaikaiseen sosiaalis-taloudelliseen kriisiin, jonka seurauksena väestön elintaso laski merkittävästi. Liikuntaja urheilutoimen alalla tänä aikana korostettiin ennen kaikkea valtion politiikan vahvistamista, alan asiantuntijoiden ja aineellisten resurssien säilyttämistä, liikuntaa ja terveyttä edistävän työn organisointia sekä valtion ylläpitämien lasten ja nuorten urheilukoulujen toiminnan tukemista. ${ }^{53}$

Neuvostourheilun tietotaito siirtyi yhteiskunnallisesta mullistuksesta huolimatta seuraavil-

\section{Rodtšenkov, Voitto tai kuolema, 56.}

53 Jevgeny Sorohov, "Liikunta- ja urheilutoiminnan järjestäminen Karjalan tasavallassa Neuvostoliiton jälkeisenä aikana vuosina 1991-2014," teoksessa Liikuntaa organisoimaan: Opas liikunnan ja urheilun toimijoille, toim. Hannu Itkonen (Joensuu: Itä-Suomen liikuntaopisto, 2014), 31. 
le sukupolville. Lisäksi monet alan toimijat jatkoivat tehtävissään urheiluvalmentajina ja -organisaattoreina. Myös farmakologisissa tehtävissä toimittiin totutuin käytännöin valtiollisesti organisoituina. Valtiollisen kontrollin purkautuminen on johtanut ylilyönteihin ja alakulttuurisiin käytäntöihin. Toki jo Neuvostoliiton aikana urheiluelämä oli täynnä noitatohtoreita eli harjaantuneita valmentajia ja joukkueenjohtajia, joista joillakin oli laaja lääke- ja yleistieteellinen koulutus." ${ }^{54}$

Viime vuosikymmenen puolivälissä Venäjällä otettiin käyttöön GTO-ohjelma. Presidentti Putinin määräyksin venäläiset velvoitettiin Neuvostoliiton käytäntöjen mukaisesti olemaan valmiita työhön ja maanpuolustukseen. Julkisuudessa onkin arvioitu, että GTO-ohjelman palauttaminen on yksi osoitus Venäjän paluusta neuvostokäytäntöihin. Voisipa ajatella niinkin, että GTO:n myötä paluun teki ruumiin kolminaisuuden tulkinta. Työn ja maanpuolustuksen rinnalle asettuu sulavasti kolmanneksi lenkiksi urheilu.

Neuvostourheilun perinnön hengessä urheilulla on keskeinen asema uusissa itsenäistyneissä valtioissa. Urheilijoiden voitot nähdään tärkeiksi identiteetin ja kansallistunteen rakennustyössä. Venäjä on halunnut osoittaa urheilun suurvalta-asemaa myös järjestämällä kansainvälisiä arvokilpailuja. Sotshin vuoden 2014 talviolympiakisojen ja jalkapalloilun vuoden 2018 MM-kisojen järjestämisestä Venäjän poliittinen johto otti irti kaiken mahdollisen imagohyödyn, jolloin tapahtumilla oli myös urheilua laajempi poliittinen merkityksensä. ${ }^{55}$

Neuvostourheilun tarkastelu osoittaa urheilun kontekstuaalisuuden. Yleisemmät yhteiskunnalliset olosuhteet ja poliittiset valinnat vaikuttavat siihen, millaisiksi urheilun asema ja merkitys muodostuvat. ${ }^{56}$ Neuvostoliitossa urheilu liitettiin NKP:n johdolla olennaiseksi osaksi ideologista kamppailua kapitalistisia maita vastaan. Urheilu palveli hyvin maapuolustuksen ja työn ruumiillisuutta, ja yhdessä ne muodostivat kiinteän järjestelmää palvelevan kolminaisuuden. Suosion kasvaessa huippu-urheilusta muotoutui yksi yhteiskuntajärjestelmien välisen kylmän sodan taistelutanner, jossa neuvostourheilijat menestyivät kiistatta hyvin. Menestyksen saavuttamiseksi käytettiin kaikki mahdolliset keinot aina farmakologisia ohjelmia myöten. Neuvostoliiton urheilun suurvalta-aika päättyi koko maan romahdukseen. Vaikka neuvostourheilu tuhoutuikin, niin sen perintö elää edelleen monin tavoin urheilun käytännöissä Venäjällä ja osin muissakin entisissä neuvostotasavalloissa.

\section{Lähteet}

Applebaum, Anne. Gulag: A History of the Soviet Camps. London: Penguin Books, 2003.

Buntsuk, M. F. Neuvostoliiton liikuntaorganisaatio. Liikuntatieteellisen Seuran julkaisu 71. Helsinki: Liikuntatieteellinen Seura, 1979.

Eichberg, Henning. "Body Culture." Teoksessa Routledge Companion to Sports History, toim. S. W Pope \& John Nauright, 162-181. London: Routledge, 2010.

Figes, Orlando. Vallankumouksen Venäjä 1891-1991. Helsinki: Siltala, 2021.

Hentilä, Seppo. Suomen työläisurheilun historia. Vol. 1, Työväen Urheiluliitto 1919-1944. Hämeenlinna: Karisto, 1982.

Itkonen, Hannu. Liikkumisen sosiologia. Tampere: Vastapaino, 2021.

Itkonen, Hannu \& Kalervo Ilmanen. "Neuvostourheilusta Venäjän sekajärjestelmään." Idäntutkimus 15 , no. 4 (2008): 18-28.

Itkonen, Hannu \& Pentti Stranius. Liikettä Venäjän Karjalassa: Tutkimus liikuntakulttuurin muutok-

54 Rodtšenkov, Voitto tai kuolema, 91.

55 Robert W. Orttung \& Sufian N. Zhemukhov, Putin's Olympics: The Sochi Games and the Evolution of Twenty-

First Century Russia (London: Routledge, 2018), 21-29.

56 Hannu Itkonen, Liikkumisen sosiologia (Tampere: Vastapaino, 2021). 
sesta. Karjalan tutkimuslaitoksen julkaisuja 137. Joensuu: Joensuun yliopisto, 2002.

Keys, Barbara. Globalizing Sport: National Rivalry and International Community in the 1930s. London: Harvard University Press, 2006.

Keys, Barbara. "Soviet Sport and Transnational Mass Culture in the 1930s." Journal of Contemporary History 38, no. 3 (2013): 413-434.

Kim, M. P. et al., toim., Neuvostoliiton historia: Sosialismin aikakausi. Moskova: Kustannusliike Edistys, 1978.

Kokkonen, Jouko. "Oikeiden olympiakisojen maa." Teoksessa Sadan vuoden olympiadi: Suomalaisen olympialiikkeen historia, toim. Vesa Tikander et al., 108-173. Porvoo: WSOY, 2007.

Lewin, Moshe. Neuvostoliiton vuosisata. Helsinki: Like Kustannus, 2006.

Makoveeva, Irina. "Soviet Sport as Cultural Phenomenon: Body and/or Intellect?." Studies in Slavic Cultures, no. 3 (2002): 9-32.

Mesham, Stuart, toim. EURO 2020: Suuri jalkapallokirja. Helsinki: Readme.fi, 2021.

Metsä-Tokila, Timo. ”Tiellä olympialaisiin: Huipulle tähtäävän urheilun ja koulutuksen yhdistäminen Neuvostoliitossa ja Venäjällä." Idäntutkimus 7, no. 3-4 (2000): 71-79.

Nygrén, Helge. Punainen olympia: TUL kansainvälisen työläisurheilun vaiheissa 1920-30-luvuilla. Helsinki: Tammi, 1968.

O'Mahony, Mike. Sport in the USSR: Physical CultureVisual Culture. London: Reaktion Books, 2006.

Orttung, Robert W. \& Sufian N. Zhemukhov. Putin's Olympics: The Sochi Games and the Evolution of Twenty-First Century Russia. London: Routledge, 2018.

Pesonen, Pekka. Venäjän kulttuurihistoria. Helsingin yliopiston Lahden tutkimus- ja koulutuskeskus, 1998.
Raschke, Joachim. "Zum Begriff der sozialen Bewegung?," Teoksessa Neue Soziale Bewegungen in der Bundesrepublik Deutschland, toim. R. Roland \& D. Rucht, 19-29. Frankfurt am Main: Campus Verlag, 1987.

Riordan, James. Sport in Soviet Society. London: Cambridge, 1977.

Riordan, James. Sport, Politics and Communism. Mancester: Manchester University Press, 1991.

Riordan, James "The Unfinished Symphony Communism and Sport." ISHPES Congress in Budapest, 1999.

Rodtšenkov, Grigori. Voitto tai kuolema: Venäjän salainen dopingohjelma. Liettua: Bazar, 2020

Sjöblom, Kenth. "Autonominen olympiamaa." Teoksessa Sadan vuoden olympiadi: Suomalaisen olympialiikkeen historia, toim. Vesa Tikander et al., 10-39. Porvoo: WSOY, 2007.

Sorohov, Jevgeny. "Liikunta- ja urheilutoiminnan järjestäminen Karjalan tasavallassa Neuvostoliiton jälkeisenä aikana vuosina 1991-2014." Teoksessa Liikuntaa organisoimaan: Opas liikunnan ja urheilun toimijoille, toim. Hannu Itkonen, 31-54. Joensuu: Itä-Suomen liikuntaopisto, 2014.

Suomela, Klaus U. Lensimme uuteen maailmaan: Nähtyä ja koettua Neuvostoliitosta. Lahti: Kansankirja, 1946.

Vares, Vesa. Pallon herruus: Kuningaslajin valta ja lumo. Helsinki: Otava, 2018.

"Olympic Football Tournament Melbourne 1956." Luettu 6.9.2021. https://www.fifa.com/tournaments/mens/mensolympic/melbourne1956.

“Olympic Games." Luettu 6.9.2021. www.olympics. com/en/olympic-games.

Zeller, Manfred. Sport and Society in the Soviet Union: The Politics of Football after Stalin. London: I.B. Tauris, 2018. 